\title{
General control non-repressible 20 (GCN20) functions in root growth by modulating DNA damage repair in Arabidopsis
}

\author{
Tong-Tong Han, Wen-Cheng Liu and Ying-Tang Lu*
}

\begin{abstract}
Background: Most $A B C$ transporters are engaged in transport of various compounds, but its subfamily $F$ lacks transmembrane domain essential for chemical transportation. Thus the function of subfamily $F$ remains further elusive.

Results: Here, we identified General Control Non-Repressible 20 (GCN20), a member of subfamily F, as new factor for DNA damage repair in root growth. While gcn20-1 mutant had a short primary root with reduced meristem size and cell number, similar primary root lengths were assayed in both wild-type and GCN20::GCN20 gcn20-1 plants, indicating the involvement of GCN2O in root elongation. Further experiments with EdU incorporation and comet assay demonstrated that gcn20-1 displays increased cell cycle arrest at G2/M checkpoint and accumulates more damaged DNA. This is possible due to impaired ability of DNA repair in gcn20-1 since gcn20-1 seedlings are hypersensitive to DNA damage inducers MMC and MMS compared with the wild type plants. This note was further supported by the observation that gcn20-1 is more sensitive than the wild type when subjected to UV treatment in term of changes of both fresh weight and survival rate.
\end{abstract}

Conclusions: Our study indicates that GCN20 functions in primary root growth by modulating DNA damage repair in Arabidopsis. Our study will be useful to understand the functions of non-transporter ABC proteins in plant growth.

Keywords: DNA damage repair, GCN20, Root elongation, Cell cycle, Root meristem

\section{Background}

Unlike animals, plants cannot change their location and thus plant roots in soil are constantly exposed to adverse environmental stresses such as high salinity, drought, free radicals, alkylating agents and heavy metals [1-5]. These adverse conditions damage DNA of the root meristem cells to affect genomic integrity and stability [6]. Root meristem accommodates stem cells that continually divide asymmetrically to produce new stem cells and daughter cells for root growth [7]. Therefore, the inhibition of the activity of root meristem by cell cycle restrains root growth and thus impairs plant growth and development [8-10].

DNA damages include base alkylation and oxidation, formation of abasic sites and pyrimidine dimers, DNA inter-strand crosslinks, single strand breaks (SSBs) and

\footnotetext{
* Correspondence: yingtlu@whu.edu.cn

State Key Laboratory of Hybrid Rice, College of Life Sciences, Wuhan University, Wuhan 430072, China
}

double strand breaks (DSBs) [11]. To cope with these DNA damages, eukaryotic cells trigger the DNA damage response (DDR) to maintain genome stability [5]. When cells undergo DNA damage, the activated cell cycle checkpoints transiently arrest cell cycle for lesion repair before the cell cycle continues. If the DNA damage is unrepairable, the cells will terminate cell division or suffer programmed cell death (PCD) [6]. Two kinases, ATM (Ataxia Telangiectasia mutated) and ATR (ATM and Rad3-related) function as main DDR regulators to coordinate cell cycle progression and activation of DNA repair pathways [4]. While ATM is mainly triggered by DSBs, ATR is activated by a broad range of lesions including UV photoproducts, DNA breaks and DNA crosslinks [12, 13]. In Arabidopsis, both active ATM and ATR can phosphorylate the transcription factor SOG1, and thus transcriptionally activate hundreds of genes involved in cell cycle arrest, DNA repair and PCD [14].

The ATP binding cassette $(\mathrm{ABC})$ transporters are engaged in transport of various compounds, including 
sugars, ions, peptides, and more complex organic molecules $[15,16]$. Its 130 members are classified into 8 subfamilies (A-H) in Arabidopsis [17, 18]. While all subfamilies except $\mathrm{E}$ and $\mathrm{F}$ have nucleotide domain (NBD) and transmembrane domain (TMD), essential for chemical transportation, the functions of subfamilies $\mathrm{E}$ and $\mathrm{F}$ containing NBD but no TMD remain further elusive [19]. General Control Non-Repressible 20 (GCN20), a member of subfamily $F$, is soluble $A B C$ protein without TMD [17]. In yeast, GCN20 promotes the kinase activity of GCN2, which is required for yeast growth under amino acid starvation [20]. In Arabidopsis, the mutation in GCN2O impairs pathogen associated molecular patterns-triggered stomatal closure [21].

In this study, we report that GCN20 is involved in root growth as a novel factor for DNA damage repair. Our results indicated that $g c n 20-1$ plant has short primary roots and the mutant phenotype can be rescued by expressing GCN2O in gcn20-1. Further experiments demonstrated that the mutation in GCN20 impairs the DNA damage repair since the mutant is hypersensitive to MMC, MMS and UVC. Thus, GCN20 is involved in root elongation by modulating DNA damage repair.

\section{Results}

GCN20 positively regulates root meristem growth

To investigate possible role of GCN2O in plant growth, we identified a T-DNA insertion allele (Salk_135770) from the Arabidopsis Biological Resource Centre as gcn20-1. PCR-based genotyping by flanking the insertion indicated that T-DNA inserts at - 43 bp upstream of the translation start site of GCN2O (Fig. 1a). Quantitative PCR (qPCR) analysis showed that the expression of GCN2O in the mutant was severely repressed (Fig. 1b). Then, we examined the growth of the mutant by measuring root lengths and found that the primary root of the mutant was shorter than that of the wild type (Fig. 1c, d), indicating a positive role of GCN2O in root growth. To further confirm it, we

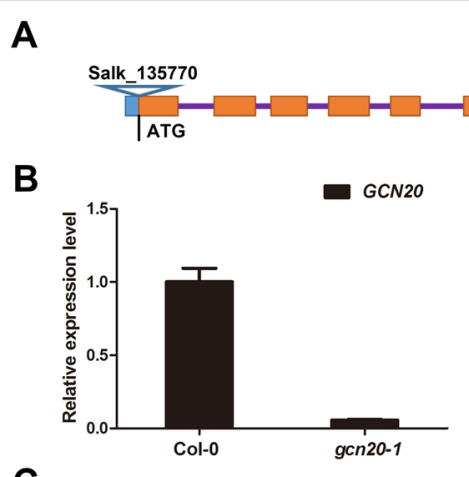

C
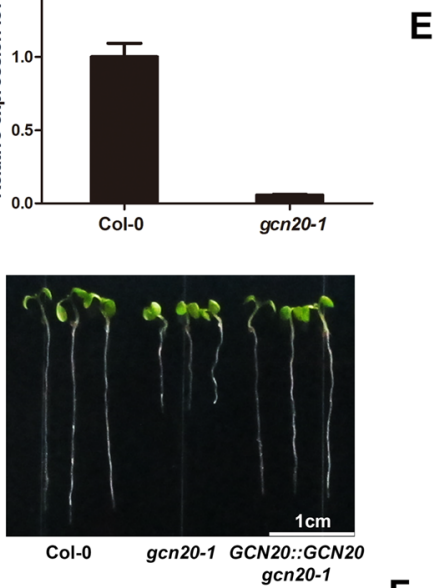

D

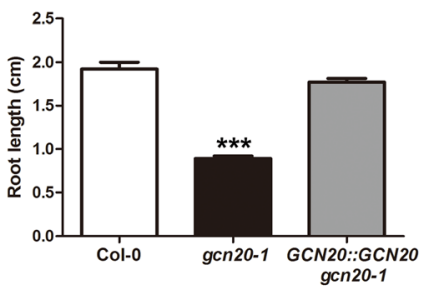

$\mathbf{F}$
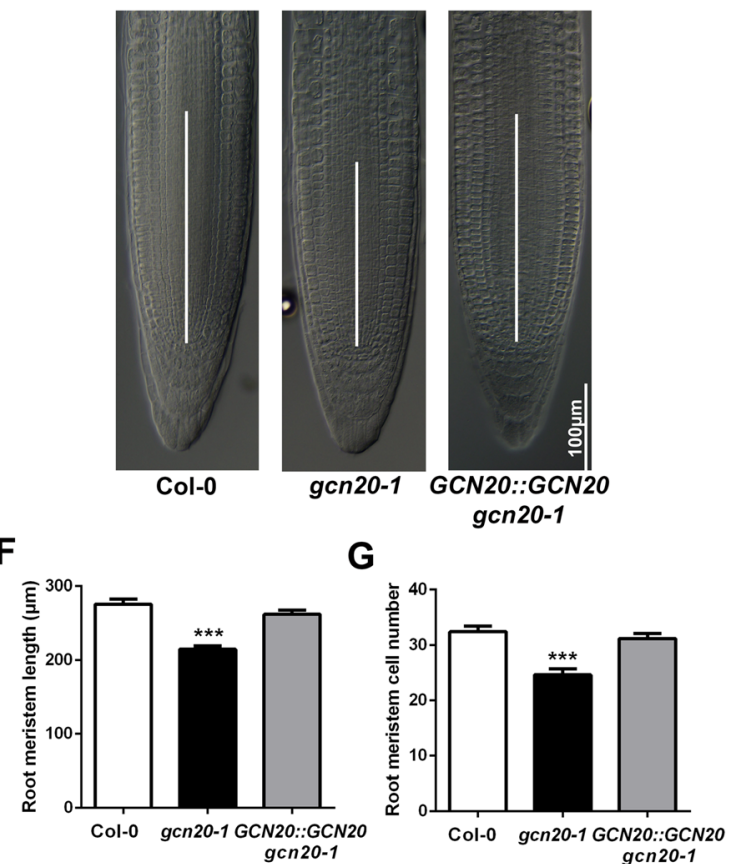

Fig. 1 The gcn20-1 mutant displays reduced root growth. a The diagram shows T-DNA insertion site in GCN20 (At1g64550) of Salk_135770 (gcn20-1). Rectangles represent exons and lines between the exons stand for introns. b The expression level of GCN20 was assayed by qPCR in the wild type and gcn20-1. The expression level of the wild type is set to 1. ACT2 was used as an internal control. c The representative images of the 6-d-old wild-type, gen20-1 and GCN20::GCN20 gen20-1 seedlings. Bar = $1 \mathrm{~cm}$. d Roots length of 6-day-old wild-type, gcn20-1 and GCN20::GCN20 gen20-1 seedlings. e The photographs for the root meristem regions of 6-day-old wild-type, gcn20-1 and GCN20::GCN20 gcn20-1 plants. Bar $=100 \mu \mathrm{m}(\mathbf{f}, \mathbf{g})$ Size (f) and cell number (G) of the root meristem of 6-day-old wild-type, gen20-1 and GCN20::GCN20 gen20-1 seedlings. Data shown are means \pm SEM. Asterisks indicate significant differences with respect to each control (Student's $t$ test): ${ }^{* * *}, P<0.001$ 
introduced the genomic sequences of GCN2O including its promoter into $g c n 20-1$ plants and assayed primary root lengths, As expected, GCN20::GCN20 gcn20-1 lines have similar root lengths as the wild type did. (Fig. 1c, d).

Shorter root is usually associated with changes of the meristem region as indicated in previous reports [22, 23]. Thus, we focused on the root meristem zone of the mutant. Indeed, decreased meristem length and cell number were assayed in $g c n 20-1$ roots compared with those in the wild type and GCN20::GCN20 gcn20-1 (Fig. 1e-g), suggesting that $G C N 20$ affects root length by regulating root meristem. To function in root meristem, GCN20 may express in root. Thus, we obtained transgenic lines GCN20::GUS and examined the spatial expression of GCN2O via GUS-staining. Our data showed that GCN20 expressed in the root meristem (Fig. 2a). In addition, GUS activity was also detected in other tissues such as anthers, stigmas and leaves. (Fig. 2b, c).

The gcn20-1 shows increased cell cycle arrest at the G2/M checkpoint

It has been reported that reduced root meristem could be due to the deficiency in cell cycle regulation [24]. Thus, we determined cell dividing in the root meristem of $g c n 20-1$ by utilizing a nucleotide analog 5-ethynyl-2'-deoxyuridine (EdU) incorporation assay, which shows actively replicating cells [25]. We found that the number of actively replicating cells in root meristems was significantly reduced in gcn2O1 compared with the wild type and GCN20::GCN20 gcn20-1 (Fig. 3a, b), implying cell cycle arrest occurring in the root meristems of $g c n 20-1$ plants. Then, we further analyzed the expression of the cell cycle related marker genes: $C D K B 1 ; 1$ (specifically activated in early $\mathrm{S}$ phase and $\mathrm{M}$ phase), KRP2 (a negative regulator of G1/S checkpoint), and WEE1 and CDKB2;1, which trigger G2/M checkpoint [7]. Our results exhibited that the expressions of KRP2 and $C D K B 1 ; 1$ were similar in the roots of wild-type, $g c n 20$ and GCN20::GCN20 gcn20-1 plants, whereas the expression of $C D K B 2 ; 1$ and WEE1 was significantly upregulated in the mutant compared with that in the wild type and GCN20::GCN2O gcn20-1 (Fig. 3c-f), suggesting that GCN2O is involved in G2/M checkpoint.

\section{GCN20 is involved for DNA damage repair}

The G2/M checkpoint is also known as G2/M DNA damage checkpoint $[7,26]$, which ensures cells to repair DNA damage before entering mitosis. Since our data above suggest a role of GCN2O in G2/M checkpoint, we further evaluated the DNA damage with a comet assay [27]. Indeed, the percentage of DNA in the tail of gcn20-1 cells was significantly higher than that in the wild type and GCN20::GCN2O gcn20-1 (Fig. 4a, b), indicating that

\section{A}
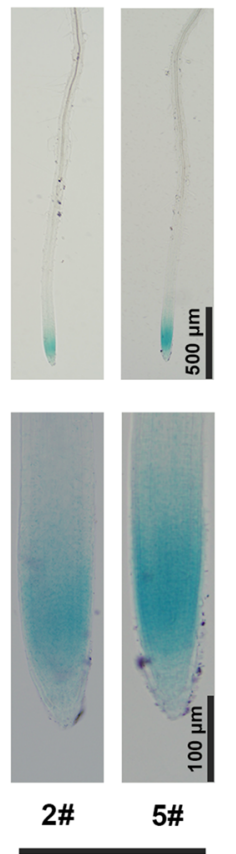

GCN20::GUS
B

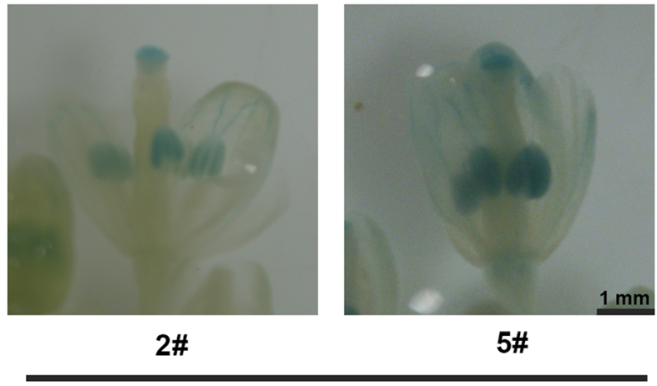

GCN20::GUS

C

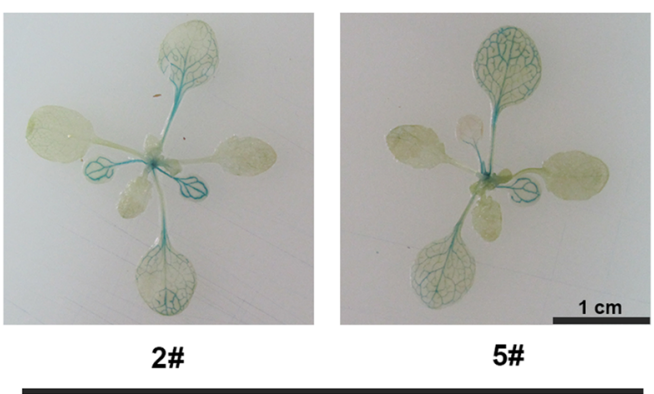

GCN20::GUS

Fig. 2 The expression pattern of GCN20. a-c GUS staining of GCN20::GUS plants in roots (a), anthers and stigmas (b) and young seedlings (c). 2\# and $5 \#$ stand for two independent lines 
A

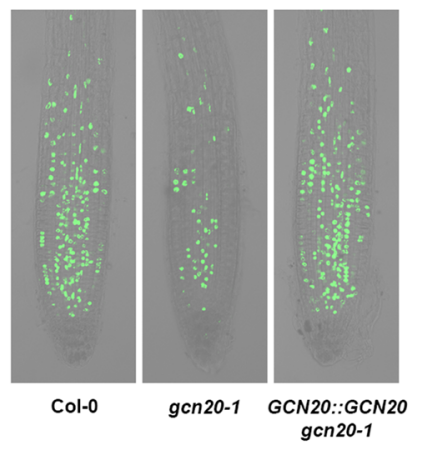

C

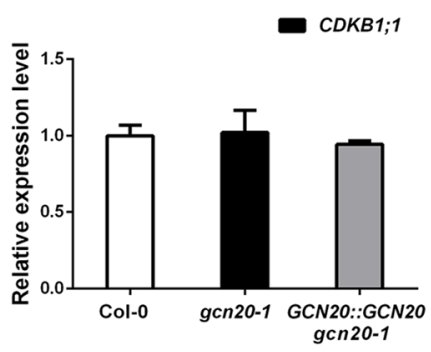

E

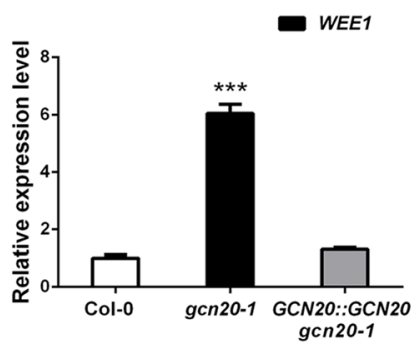

B

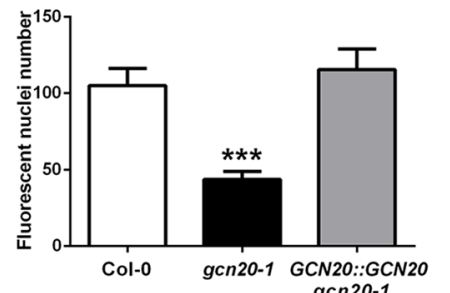

D
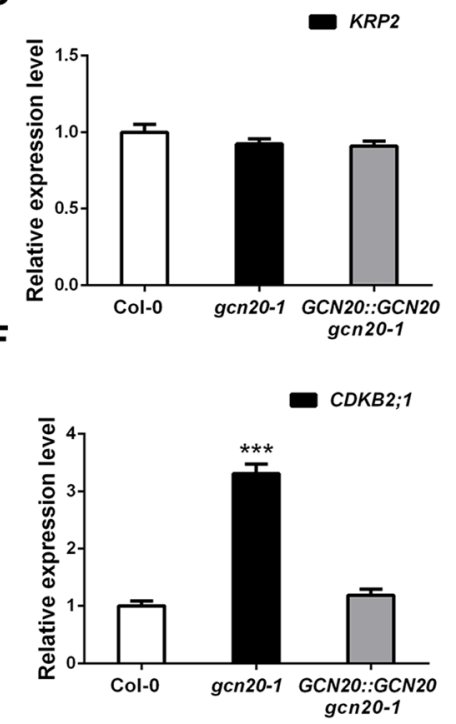

Fig. 3 The mutation in GCN20 results in cell cycle arrest at G2/M phase. a Analysis of cellular DNA replication in wild-type, gcn20-1 and GCN20::GCN20 gcn20-1 plants by an EdU incorporation assay. b Fluorescence nuclei number of wild-type, gcn20-1 and GCN20::GCN20 gcn20-1 root meristems in EdU incorporation assay. c-f The expression of CDKB1;1 (c), KRP2 (b), WEE1 (e) and CDKB2;1 (f) were assayed by qPCR in the wild type, gcn20-1 and GCN20::GCN20 gcn20-1. The expression level of the wild type is set to 1 and ACT2 was used as an internal control. Data shown are means \pm SEM. Asterisks indicate significant differences with respect to each control (Student's $t$ test): ${ }^{* *}, P<0.001$

gcn20-1 has more damaged DNA. To further confirm this, we analyzed the expression of several DNA damage-induced genes: KU70, KU80 and RAD51 [28, 29]. Our qPCR analysis showed that all of these three genes were significantly upregulated in $g c n 20-1$ in comparison with those in the wild type and GCN20::GCN20 gcn20-1 (Fig. 4c-e), further supporting that the mutation in GCN20 results in higher accumulation of damaged DNA.

The higher accumulation of damaged DNA in $g c n 20-1$ could be due to impaired ability of DNA repair [11]. Thus, we further tested the sensitivity of gcn20-1 to DNA damage inducing agent methyl methanesulfonate (MMS) and mitomycin $\mathrm{C}$ (MMC), which has been wildly used to verify gene function in DNA damage repair [7, 30-32]. When treated with DSB-inducing agent MMS, the gcn20-1 mutant was much more sensitive than the wild type and
GCN20::GCN20 gcn20-1 plants in term of changes in fresh weights of treated $g c n 20-1$, wild-type and GCN20::GCN20 gcn20-1 plants compared with untreated controls, respectively (Fig. 5a-c). We also assessed the survival rates of wild-type, $g c n 20-1$ and GCN20::GCN20 gcn20-1 plants treated with inter-strand crosslinking agent MMC. The survival rates were up to $84.47 \%$ for wild-type plants but only $17.03 \%$ for $g c n 20-1$ plants when subjected to $30 \mu \mathrm{M}$ MMC (Fig. 5d-f), further revealing that the ability of DNA damage repair is impaired in gcn20-1. Taken together, our data our data suggest that GCN2O is involved in DNA damage repair.

\section{The gcn20-1 mutant is sensitive to UV light}

It is well-known that UV inhibits plant growth by inducing DNA damage [33]. Therefore, we also examined 


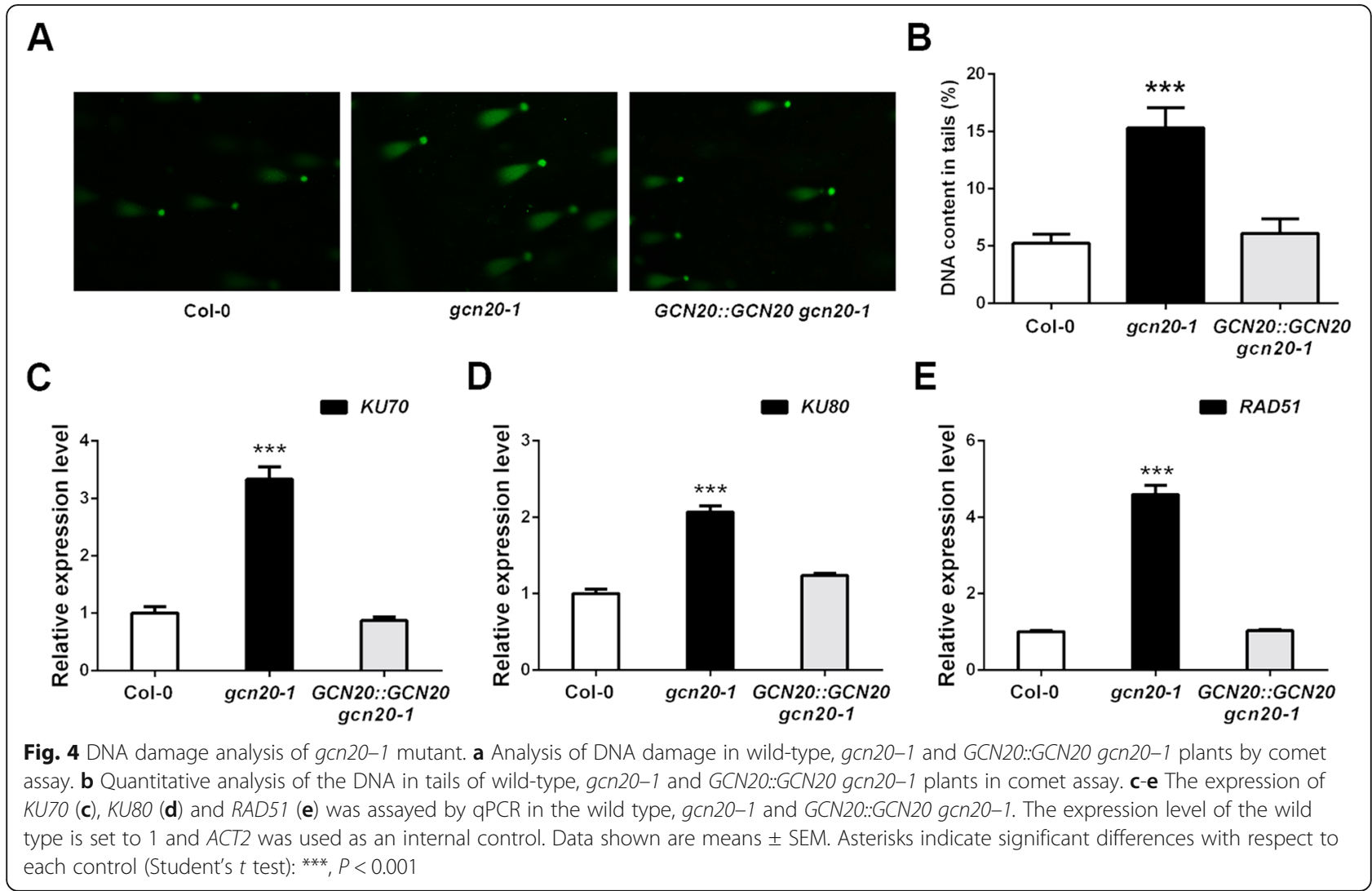

whether gcn20-1 with impaired ability of DNA repair is more sensitive to UV treatment. For this purpose, we assayed both fresh weight and survival rates of gcn20-1 plants treated with UVC. While fresh weight of treated gcn $20-1$ was reduced to $14.36 \%$ compared with untreated control, up to $74.73 \%$ fresh weight of wild-type seedlings was assayed (Fig. $6 \mathrm{a}-\mathrm{c}$ ), indicating that the effect of UVC treatment is more pronounced in gcn20-1 seedlings compared with wild-type plants. Similarly, the wild type had much higher survival rate $(83.75 \%)$ than $45.13 \%$ of $g c n 20-1$ seedlings when treated with high dose UVC (Fig. 6d). These data suggested that impaired ability of DNA repair in gcn20-1 is responsible for higher sensitivity of $g c n 20-1$ to UVC treatment in comparison with the wild type.

\section{Discussion}

The ATP binding cassette transporters have been implicated in the transport of various compounds [16]. However, the members of its subfamilies $\mathrm{E}$ and $\mathrm{F}$ do not contain transmembrane domain, which is essential for chemical transportation [17]. Thus, the function of these subfamilies remains enigmatic. Arabidopsis GCN20, a member of subfamily $\mathrm{F}$, shares sequence similarities with yeast (46\% identity and $66 \%$ similarity) and mammalian (41\%identity and $61 \%$ similarity) GCN20 proteins (EDN59158 and
NP_038880, respectively) [21]. Previous reports showed that yeast GCN20 promotes the kinase activity of GCN2 [20] and the mutation in GCN20 impairs pathogen associated molecular patterns-triggered stomatal closure [21]. Here, we demonstrated that GCN20 is involved in primary root elongation by regulating meristem size and cell number.

Root growth is determined by meristem cell division and subsequently cell elongation/differentiation [22]. In the root meristem, the meristematic activity of stem cells is modulated by both developmental and environmental factors [24]. Our study showed that the gcn20-1 plants have shorter primary roots with shorter meristem size and reduced cell number than the wild type, indicating a positive role of GCN20 in root growth. Consistent its function in root growth, GCN20 expresses in root tip including root meristem. This gene is also expressed in leaves, consistent with the finding by Zeng et al. that gcn20-1 plants have pale green leaves [21].

Cell cycle arrest in root meristem impairs plant growth and development [8]. Cell cycle arrest can be restrained by checkpoints and cell cycle checkpoints provide the cells with sufficient time to either cope with the damaged DNA or undergo cell death $[14,34]$. In particular, the $G 2 / M$ checkpoint allows cells to repair replication errors and damages before proceeding into mitosis [6]. 
A

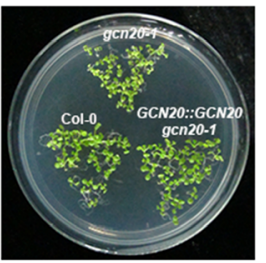

Mock

B

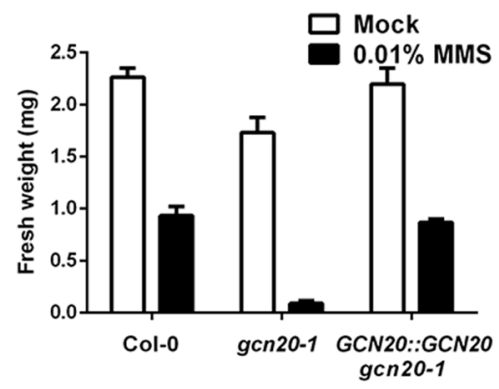

C

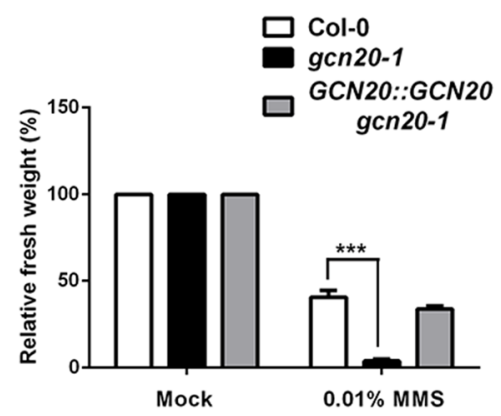

$0.01 \%$ MMS
D

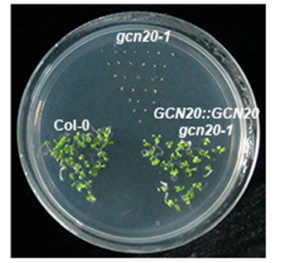

E

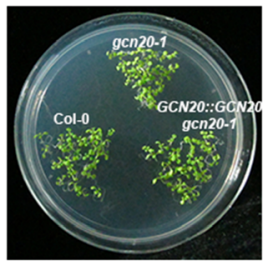

Mock
$30 \mu \mathrm{M} M M C$

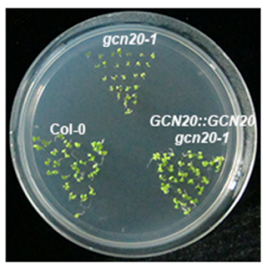

E

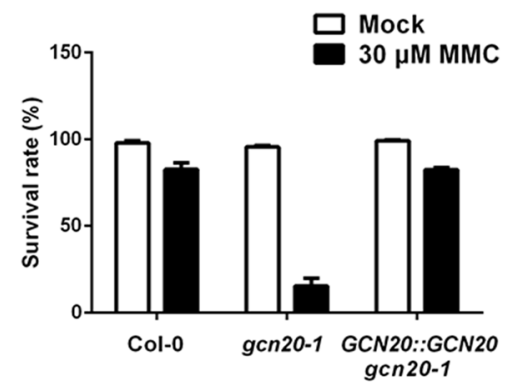

F

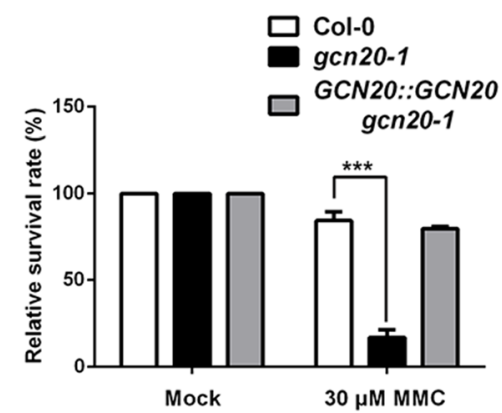

Fig. 5 The gcn20-1 mutant is sensitive to chemically induced DNA damage. a The wild type, gcn20-1 and GCN20::GCN20 gcn20-1 were grown with or without $0.01 \%$ MMS for 12 days before photographed. $\mathbf{b}$ Quantitative analysis of fresh weights of wild-type and gcn20-1 and GCN20::GCN20 gen20-1 plants grown with or without 0.01\% MMS for 12 days. c Relative fresh weights of wild-type, gCn20-1 and GCN20::GCN20 gcn20-1 plants treated with $0.01 \%$ MMS for 12 days compared with their untreated control. $\mathbf{d}$ The wild type and gcn20-1 and GCN20::GCN20 gcn20-1 were grown with or without $30 \mu \mathrm{M} \mathrm{MMC}$ for 12 days before photographed. e Quantitative analysis of survival rates of wild-type and gcn20-1 and GCN20::GCN20 gen20-1 plants grown with or without $30 \mu \mathrm{M}$ MMC treatment for 12 days. $\mathbf{f}$ Relative survival rates of wild-type, gcn20-1 and GCN20::GCN20 gcn20-1 plants treated with $30 \mu \mathrm{M}$ MMC for 12 days compared with their untreated control. Seedlings were scored survival when plants had two or more true leaves. Data shown are means \pm SEM. Asterisks indicate significant differences with respect to each control (Student's $t$ test): ${ }^{* *}, P<0.001$

Our EdU incorporation assay showed that the number of actively replicating cells in gcn20-1 root meristems is reduced compared with the wild type. Further, the expression of $C D K B 2 ; 1$ and WEE1 is significantly upregulated in the mutant compared with that in the wild type, suggesting that GCN20 is involved in G2/M checkpoint.

Since DNA damage leads to a cell cycle arrest, DNA damage repair also modulate the root meristem cell division [26]. For example, RCC1/UVR8/GEF-Like 3 (RUG3) modulates root meristem activity by regulating DDR, and cell cycle progression [7]. We indicated that GCN20 functions in root growth. The NBDs of the $\mathrm{ABC}$ proteins, necessary for chemical transport, are engaged in ATP binding and cleavage [17]. This domain is present not only in $A B C$ transporters but also in a variety of non-transporter $A B C$ proteins. Many non-transporter $\mathrm{ABC}$ proteins such as Radiation sensitive $50(\operatorname{Rad} 50)$ and Mutator gene $S(M u t S)$ are involved in DNA repair [35]. In our study, we also suggest that non-transporter $A B C$ protein GCN20 is involved in DNA repair as $g c n 20-1$ accumulates more damaged DNA.

It is reported that UVC, MMS and MMC trigger different types of DNA damage [30, 36-38]. UVC brings cyclobutane pyrimidine dimers in DNA, MMS is DSB-inducing agent and MMC triggers inter-strand crosslinking. In Arabidopsis, ATM and ATR function as main DDR regulators to coordinate cell cycle progression and the activation of 


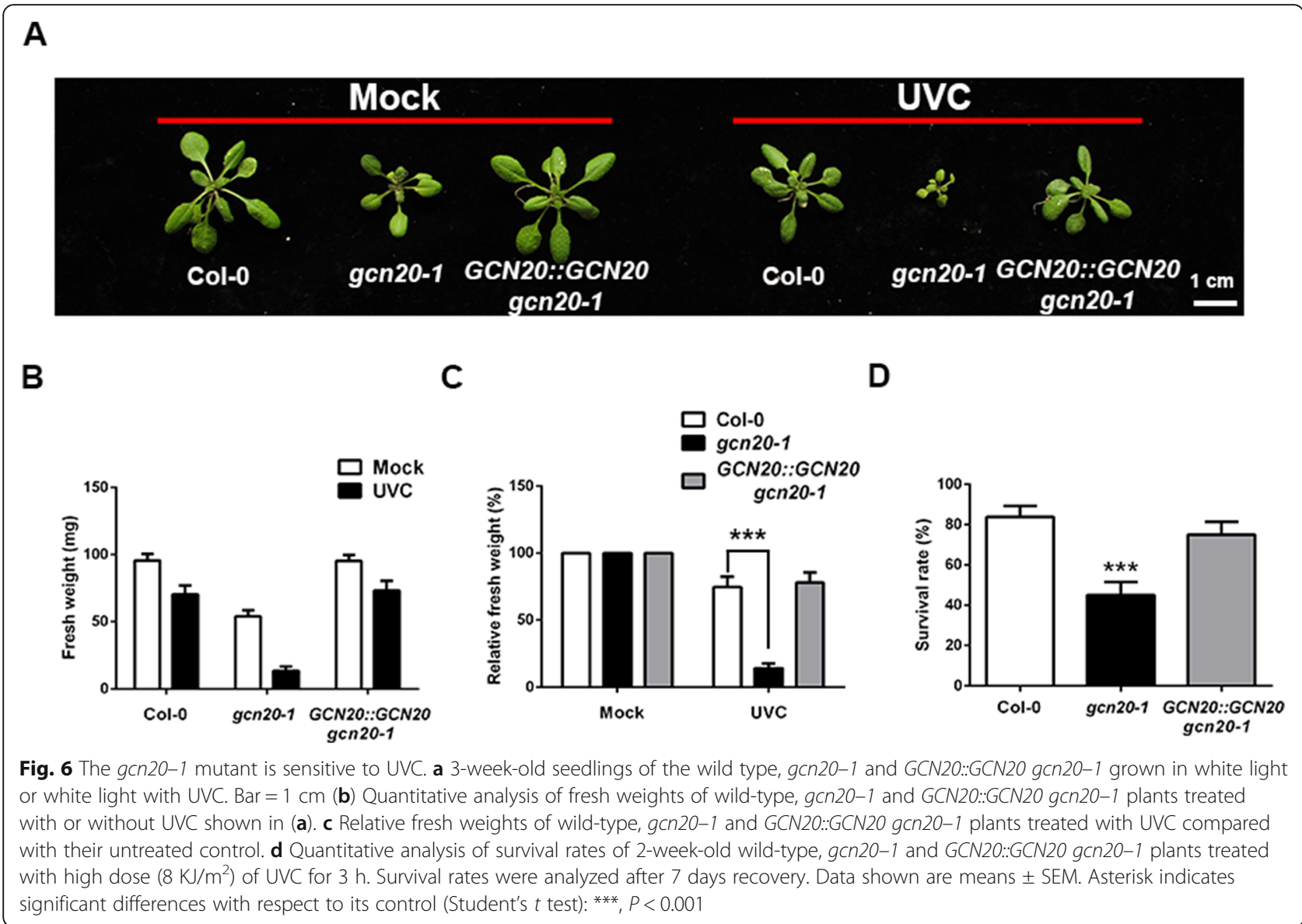

DNA repair pathways [4]. While DSBs trigger ATM activation, UV photoproducts, DNA breaks and DNA crosslinks promote ATR activation. Both ATM and ATR phosphorylate the transcription factor SOG1, and thus transcriptionally activate the expression of hundreds of genes involved in DNA repair [6, 39]. Our results showed that $g c n 20-1$ was more sensitive to all the three agents (MMC, MMS and UVC), suggesting that GCN20 may function downstream of ATM/ATR pathways.

\section{Conclusion}

In summary, GCN20 functions in root growth by changes of damaged DNA accumulation probably through DNA damage repair. Our study will be useful to understand the functions of non-transporter $\mathrm{ABC}$ proteins in plant growth. However, further studies are required to reveal the molecular mechanism of GCN20 in DNA damage repair.

\section{Methods}

Plant materials and growth conditions

The line Salk_135770 was obtained from Arabidopsis Biological Resource Centre. Arabidopsis thaliana seeds were surface sterilized with $5 \%$ chloros for $5 \mathrm{~min}$, washed three times with sterile water, placed at $4{ }^{\circ} \mathrm{C}$ for
3 days, and then planted on $1 / 2$ MS medium [40] with $0.8 \%$ agar and $1 \%$ sucrose, $\mathrm{pH} 5.8$ at $23{ }^{\circ} \mathrm{C}$ and $100 \mu \mathrm{mol} \mathrm{m} \mathrm{m}^{-2} \mathrm{~s}^{-1}$ illumination under $16 \mathrm{~h}$ light $/ 8 \mathrm{~h}$ dark conditions $[41,42]$.

\section{Vector constructs and transgenic lines}

To make GCN20::GCN20 construct, the $8 \mathrm{~kb}$ genomic sequence of Arabidopsis GCN2O including $3 \mathrm{~kb}$ upstream sequence of start codon and $1 \mathrm{~kb}$ downstream sequence of stop codon was amplified using PCR with specific primers, inserted into pCambia1300 vector at $\mathrm{BamH}$ I site and confirmed by sequencing. For GCN20::GUS construct, the $3 \mathrm{~kb}$ upstream sequence of GCN2O start codon was inserted into BamH I/Nco I-digested pCambia1301. GCN20::GCN20 construct was transformed into gcn20-1 mutant and GCN20::GUS construct into the wild type by Agrobacterium tumefaciens strain GV3101 using the floral dip method as we previously reported [22]. Primers used in this study were listed in Additional file 1: Table S1.

\section{Measurement of root length}

Seeds were germinated on 1/2 MS medium as described above and grown in a vertical position. Digital images of seedlings were captured for subsequent measurement of 
the lengths of roots, Root lengths were measured by using a line traced along the root.

\begin{abstract}
Measurement of root meristem size and cell number Measurement were performed according to our previously described method [43]. Seeds were germinated on half-strength MS medium containing 1\% sucrose and $0.8 \%$ agar and grown in a vertical position. The number of root meristem cells was defined by counting the number of cells in a file extending from the initial cell adjacent to the QC to the first elongated cell in the cortex layer. Meristem size was measured from the QC to the first elongated cell in the cortex layer. Results presented are averages of more than 30 seedlings and experiments were repeated at least three times.
\end{abstract}

\section{Microscopic analyses}

For the observation of the root meristem zone and GUS staining, the seedlings were mounted with clearing solution $(8 \mathrm{~g}$ of chloral hydrate, $2 \mathrm{ml}$ of water and $1 \mathrm{ml}$ of glycerol) on glass slides, examined under an Olympus BX60 differential interference contrast (DIC) microscope and photographed by a charge-coupled device (CCD) Olympus dp72 [44].

Confocal microscopy was performed using an Olympus FluoView 1000 confocal laser-scanning microscope according to the manufacturer's instructions. $20 \mu \mathrm{g} \mathrm{ml}^{-1}$ propidium iodide (PI) staining were used in PI staining assay.

\section{RNA extraction and gene expression analysis}

RNA extraction and qPCR were performed according to our previously described method [43]. Total RNA extraction was performed using PureLink ${ }^{\text {Tix }}$ Plant RNA Reagent (Invitrogen) according to the manufacturer's instruction. RNA samples were then treated with RQ1 RNase-free DNase I (Promega) to remove DNA. The reverse transcription was carried out by using ReverTra Ace $^{\circ}$ (Toyobo). RNA was quantified by Qubit 3.0 Fluorometer nucleic acid detector (Life). $200 \mathrm{ng}$ total RNA added in each reverse transcription reaction. qPCR assay was performed by using a CFX $96^{\text {tw }}$ Real-Time PCR Detection System (Bio-Rad) with ACT2 (AT3G18780) as the reference gene. No-template controls were performed for each pair of primers. PCR was performed as follows: 3 min at $95^{\circ} \mathrm{C}$, followed by 40 cycles of denaturation for $15 \mathrm{~s}$ at $95^{\circ} \mathrm{C}$, annealing for $15 \mathrm{~s}$ at $58{ }^{\circ} \mathrm{C}$ and extension for $20 \mathrm{~s}$ at $72{ }^{\circ} \mathrm{C}$. Relative expression was analyzed by $\Delta \Delta \mathrm{C}(\mathrm{t})$. Melt curves analysis were assigned as follows: $65{ }^{\circ} \mathrm{C}$ to $95{ }^{\circ} \mathrm{C}$, increment $0.5{ }^{\circ} \mathrm{C}$. Efficiency of reactions were considered to $100 \%$. All experiments were performed with three independent biological replicates and three technical repetitions. The genes specific primers used are listed in Additional file 1: Table S1.

\section{GUS staining}

GUS staining was performed based on the procedures as previously described [23]. In brief, plants were incubated in staining solution: $100 \mathrm{mM}$ sodium phosphate buffer, $\mathrm{pH}$ 7.5, containing $1 \mathrm{mM}$ 5-bromo-chloro-3indolyl- $\beta$-D-glucuronide, $\quad 0.5 \mathrm{mM} \quad \mathrm{K} 3[\mathrm{Fe}(\mathrm{CN}) 6]$ and $0.5 \mathrm{mM} \mathrm{K} 4[\mathrm{Fe}(\mathrm{CN}) 6], 10 \mathrm{mM}$ EDTA, pH 8.0 and $0.1 \%$ Triton $\mathrm{X}-100$ at $37^{\circ} \mathrm{C}$. The staining time depended on different tissues of the transgenic lines.

\section{EdU incorporation assay}

EdU incorporation assay was performed as previously described [25]. The wild-type and gcn20-1 plants were grown on $1 / 2 \mathrm{MS}$ agar plate for 5 days and then incubated in $1 / 2$ MS liquid medium with $10 \mu \mathrm{M}$ 5-Ethynyl-2'-deoxyuridine (EdU) (Invitrogen, Carlsbad, CA, USA) for $30 \mathrm{~min}$. Then the seedlings were fixed for $30 \mathrm{~min}$ in $4 \%(w / v)$ formaldehyde solution in phosphate buffered saline (PBS) with $0.1 \%$ Triton $\mathrm{X}-100$. Following $3 \times 10 \mathrm{~min}$ PBS washes, the seedlings were incubated for $30 \mathrm{~min}$ at room temperature in EdU detection cocktail (RiboBio, Cell-Light $^{\mathrm{m}}$ Apollo stain Kit) followed by a $10 \mathrm{~min}$ rinse. Finally, the root tips of wild-type and gcn20-1 seedlings were imaged with Laser-scanning confocal microscope using the Argon laser $488 \mathrm{~nm}$ excitation and $478-553 \mathrm{~nm}$ emission lines. The fluorescent nuclei represent actively incorporating (replicating) nuclei.

\section{Comet assay}

Comet assay was performed as described by Menke et al. [36]. About 75-150 $\mathrm{mg}$ of the plant material were prepared for the comet assay. The comet assay was performed in a darkroom with dim red light. Microscopic slides were precoated with a layer of $1 \%$ normal melting point agarose and thoroughly dried at $60{ }^{\circ} \mathrm{C}$. The seedlings were sliced with a razor blade in 300-400 $\mu$ l PBS $\left(160 \mathrm{mM} \mathrm{NaCl}, 4 \mathrm{mM} \mathrm{NaH} \mathrm{PO}_{4}, 8 \mathrm{mM} \mathrm{Na} \mathrm{HPO}_{4}\right.$, $\mathrm{pH}$ 7.0) containing $50 \mathrm{mM}$ EDTA. Two drops of $30 \mu \mathrm{l}$ nuclei suspension were dropped separately on each slide, mixed with the same volume of liquid $1 \%$ low melting point agarose at $42{ }^{\circ} \mathrm{C}$ and covered with a coverglass. Nuclei were then subjected to high salt lysis buffer (2.5 M NaCl, $100 \mathrm{mM}$ EDTA, $10 \mathrm{mM}$ Tris-HCl, $\mathrm{pH}$ 7.5) for $20 \mathrm{~min}$ at room temperature. Equilibration for $3 \times$ $5 \mathrm{~min}$ in $1 \times \mathrm{TBE}(90 \mathrm{mM}$ Tris-borate, $2 \mathrm{mM}$ EDTA, $\mathrm{pH}$ 8.4) buffer on ice was followed by electrophoresis at room temperature in $1 \times \mathrm{TBE}$ buffer at $30 \mathrm{~V}(1 \mathrm{~V} / \mathrm{cm}$, 15-17 $\mathrm{mA}$ ) for $6 \mathrm{~min}$. The comets were visualized by staining with SYBR Green I, and then photographed using microscope. At least 50 nuclei for each material were photographed, then the data were analyzed by Casp_1.2.3b2 software. 


\section{Mutagen sensitivity assay}

MMS and MMC sensitivity assay were performed according to the previous described [37, 45, 46]. The seeds were plated on $1 / 2$ MS medium with $0.8 \%$ agar and $1 \%$ sucrose, stratified in the dark at $4{ }^{\circ} \mathrm{C}$ for 3 days, and transferred to $1 / 2 \mathrm{MS}$ medium with $0.8 \%$ agar and $1 \%$ sucrose containing $0.01 \%$ MMS or $30 \mu \mathrm{M}$ MMC. MMC solutions were made in DMSO at $50 \mathrm{mM}$ for stock. MMS and MMC were added into the medium at approximate $60{ }^{\circ} \mathrm{C}$. The plates were placed in the growth chambers with $16 \mathrm{~h}$ light $/ 8 \mathrm{~h}$ dark conditions at $23{ }^{\circ} \mathrm{C}$ for 12 days and the seedling were used for the assays of fresh weight or survival rate. For fresh weight analysis, the seedlings were wiped off medium and weighed. For survival rate analysis, the seedlings were counted when the plants had two or more true leaves.

\section{UVC sensitivity assay}

UVC sensitivity assay was performed as previously reported by Rosa et al. [30]. UVC were derived from UVC light tube (G13, CnLight), and the dose of UVC were detected by UVC illuminometer (ST-512, SENTRY). For fresh weight analysis, the seedlings were grown in vermiculite under $16 \mathrm{~h}$ light $/ 8 \mathrm{~h}$ dark at $23{ }^{\circ} \mathrm{C}$ for a week. Then, the seedlings were transferred into a chamber under the same growth condition but with additional $2 \mathrm{~kJ} / \mathrm{m}^{2}$ UVC for additional 2 weeks and used for fresh weight assay. For survival rate analysis, the seedlings were grown in vermiculite under $16 \mathrm{~h}$ light $/ 8 \mathrm{~h}$ dark at $23{ }^{\circ} \mathrm{C}$ for 2 week and then subjected to additional $8 \mathrm{~kJ} /$ $\mathrm{m}^{2} \mathrm{UVC}$ for $3 \mathrm{~h}$. The treated seedling were grown under $16 \mathrm{~h}$ light/ $8 \mathrm{~h}$ dark at $23{ }^{\circ} \mathrm{C}$ for 1 week recovery and used for survival rates by counting green seedlings as previous report.

\section{Statistical analysis}

All experiments were performed with at least three repetitions. The significance of differences was determined by Student's $t$ test, as indicated in the figure legends.

\section{Additional file}

Additional file 1: Table S1. List of the primers used in this study. (DOCX $15 \mathrm{~kb}$ )

\section{Abbreviations}

ABC: ATP binding cassette; ATM: Ataxia Telangiectasia mutated; ATR: ATM and Rad3-related; DDR: DNA damage response; DSBs: double strand breaks; EdU: 5-ethynyl-2'-deoxyuridine; GCN20: General Control Non-Repressible 20; MMC: Mitomycin C; MMS: Methyl methanesulfonate; NBD: Nucleotide domain; NBD: Nucleotide domain; PCD: Programmed cell death; SSBs: Single strand breaks; UVC: Ultraviolet C

\section{Funding}

This work was supported by the National Natural Science Foundation of China (\#31470378).

\section{Availability of data and materials}

All data generated and analysed during this study are included in this published article.

\section{Authors' contributions}

$\mathrm{TTH}$ carried out most experiments and analyzed the data. YTL and TTH wrote the manuscript. TTH and WCL analyzed the data. All authors read and approved the final manuscript.

Ethics approval and consent to participate

Not applicable

Consent for publication

Not applicable

\section{Competing interests}

The authors declare that they have no competing interests.

\section{Publisher's Note}

Springer Nature remains neutral with regard to jurisdictional claims in published maps and institutional affiliations.

Received: 2 October 2017 Accepted: 27 September 2018

Published online: 12 November 2018

\section{References}

1. Roy S, Singh SK, Choudhury SR, Sengupta DN. An insight into the biological functions of family X-DNA polymerase in DNA replication and repair of plant genome. Plant Signal Behav. 2009;4(7):678-81.

2. Roy S, Roy Choudhury S, Das K. The interplay of DNA polymerase lambda in diverse DNA damage repair pathways in higher plant genome in response to environmental and genotoxic stress factors. Plant Signal Behav. 2013;8(1): e22715.

3. Tuteja N, Ahmad P, Panda BB, Tuteja R. Genotoxic stress in plants: shedding light on DNA damage, repair and DNA repair helicases. Mutat Res. 2009; 681(2-3):134-49.

4. Waterworth WM, Drury GE, Bray CM, West CE. Repairing breaks in the plant genome: the importance of keeping it together. New Phytologist. 2011; 192(4):805-22.

5. Yoshiyama KO, Sakaguchi K, Kimura S. DNA damage response in plants: conserved and variable response compared to animals. Biology. 2013;2(4): 1338-56.

6. Hu Z, Cools T, De Veylder L. Mechanisms used by plants to cope with DNA damage. Annu Rev Plant Biol. 2016;67:439-62.

7. Su C, Zhao H, Zhao Y, Ji H, Wang Y, Zhi L, Li X. RUG3 and ATM synergistically regulate the alternative splicing of mitochondrial nad2 and the DNA damage response in Arabidopsis thaliana. Sci Rep. 2017;7:43897.

8. Ji H, Liu L, Li K, Xie Q, Wang Z, Zhao X, Li X. PEG-mediated osmotic stress induces premature differentiation of the root apical meristem and outgrowth of lateral roots in wheat. J Exp Bot. 2014;65(17):4863-72.

9. Kurth $\mathrm{E}$, Cramer GR, Lauchli A, Epstein E. Effects of $\mathrm{NaCl}$ and $\mathrm{CaCl}(2)$ on cell enlargement and cell production in cotton roots. Plant Physiol. 1986;82(4): 1102-6.

10. Balestrazzi A, Confalonieri M, Macovei A, Dona M, Carbonera D. Genotoxic stress and DNA repair in plants: emerging functions and tools for improving crop productivity. Plant Cell Rep. 2011;30(3):287-95.

11. Roy S. Maintenance of genome stability in plants: repairing DNA double strand breaks and chromatin structure stability. Front Plant Sci. 2014;5:487.

12. Sweeney PR, Britt AB, Culligan KM. The Arabidopsis ATRIP ortholog is required for a programmed response to replication inhibitors. Plant J. 2009; 60(3):518-26.

13. Zou L, Elledge SJ. Sensing DNA damage through ATRIP recognition of RPAssDNA complexes. Science. 2003;300(5625):1542-8

14. Yoshiyama KO, Kimura S, Maki H, Britt AB, Umeda M. The role of SOG1, a plant-specific transcriptional regulator, in the DNA damage response. Plant Signal Behav. 2014;9(4):e28889.

15. Bauer BE, Wolfger $H$, Kuchler $K$. Inventory and function of yeast $A B C$ proteins: about sex, stress, pleiotropic drug and heavy metal resistance. Biochim Biophys Acta. 1999;1461(2):217-36. 
16. Sanchez-Fernandez R, Davies TG, Coleman JO, Rea PA. The Arabidopsis thaliana ABC protein superfamily, a complete inventory. J Biol Chem. 2001; 276(32):30231-44.

17. Verrier PJ, Bird D, Burla B, Dassa E, Forestier C, Geisler M, Klein M, Kolukisaoglu U, Lee $Y$, Martinoia $E$, et al. Plant ABC proteins--a unified nomenclature and updated inventory. Trends Plant Sci. 2008;13(4):151-9.

18. Hwang JU, Song WY, Hong D, Ko D, Yamaoka Y, Jang S, Yim S, Lee E, Khare $D$, Kim K, et al. Plant ABC transporters enable many unique aspects of a terrestrial Plant's lifestyle. Mol Plant. 2016;9(3):338-55.

19. Hopfner KP. Invited review: architectures and mechanisms of ATP binding cassette proteins. Biopolymers. 2016;105(8):492-504.

20. Garcia-Barrio M, Dong J, Ufano S, Hinnebusch AG. Association of GCN1GCN20 regulatory complex with the N-terminus of elF2alpha kinase GCN2 is required for GCN2 activation. EMBO J. 2000;19(8):1887-99.

21. Zeng W, Brutus A, Kremer JM, Withers JC, Gao X, Jones AD, He SY. A genetic screen reveals Arabidopsis stomatal and/or apoplastic defenses against Pseudomonas syringae pv. Tomato DC3000. PLoS Pathog. 2011; 7(10):e1002291.

22. Hong LW, Yan DW, Liu WC, Chen HG, Lu YT. TIME FOR COFFEE controls root meristem size by changes in auxin accumulation in Arabidopsis. J Exp Bot. 2014;65(1):275-86.

23. Yuan HM, Xu HH, Liu WC, LU YT. Copper regulates primary root elongation through PIN1-mediated auxin redistribution. Plant Cell Physiol. 2013;54(5): 766-78

24. West $\mathrm{G}$, Inze D, Beemster GT. Cell cycle modulation in the response of the primary root of Arabidopsis to salt stress. Plant Physiol. 2004;135(2):1050-8.

25. Aklilu BB, Soderquist RS, Culligan KM. Genetic analysis of the replication protein a large subunit family in Arabidopsis reveals unique and overlapping roles in DNA repair, meiosis and DNA replication. Nucleic Acids Res. 2014:42(5):3104-18.

26. De Schutter K, Joubes J, Cools T, Verkest A, Corellou F, Babiychuk E, Van Der Schueren E, Beeckman T, Kushnir S, Inze D, et al. Arabidopsis WEE1 kinase controls cell cycle arrest in response to activation of the DNA integrity checkpoint. Plant Cell. 2007:19(1):211-25.

27. Ribas-Maynou J, Gawecka JE, Benet J, Ward WS. Double-stranded DNA breaks hidden in the neutral comet assay suggest a role of the sperm nuclear matrix in DNA integrity maintenance. Mol Hum Reprod. 2014;20(4): 330-40

28. Tamura K, Adachi Y, Chiba K, Oguchi K, Takahashi H. Identification of Ku70 and Ku80 homologues in Arabidopsis thaliana: evidence for a role in the repair of DNA double-strand breaks. Plant J. 2002;29(6):771-81.

29. Culligan KM, Robertson CE, Foreman J, Doerner P, Britt AB. ATR and ATM play both distinct and additive roles in response to ionizing radiation. Plant J. 2006;48(6):947-61.

30. Rosa M, Von Harder M, Cigliano RA, Schlogelhofer P, Mittelsten Scheid O. The Arabidopsis SWR1 chromatin-remodeling complex is important for DNA repair, somatic recombination, and meiosis. Plant Cell. 2013;25(6):1990-2001.

31. Hartung F, Suer S, Bergmann T, Puchta $H$. The role of AtMUS81 in DNA repair and its genetic interaction with the helicase AtRecQ4A. Nucleic Acids Res. 2006;34(16):4438-48

32. Costa RM, Morgante PG, Berra CM, Nakabashi M, Bruneau D, Bouchez D, Sweder KS, Van Sluys MA, Menck CF. The participation of AtXPB1, the XPB/ RAD25 homologue gene from Arabidopsis thaliana, in DNA repair and plant development. Plant J. 2001;28(4):385-95.

33. Roy S, Choudhury SR, Singh SK, Das KP. AtPollambda, a homolog of mammalian DNA polymerase lambda in Arabidopsis thaliana, is involved in the repair of UV-B induced DNA damage through the dark repair pathway. Plant Cell Physiol. 2011;52(2):448-67.

34. Wang $\mathrm{L}$, Chen $\mathrm{H}$, Wang $\mathrm{C}, \mathrm{Hu} \mathrm{Z}$, Yan S. Negative regulator of E2F transcription factors links cell cycle checkpoint and DNA damage repair. Proc Natl Acad Sci U S A. 2018;115(16):E3837-45

35. Braz AS, Finnegan J, Waterhouse P, Margis R. A plant orthologue of RNase $L$ inhibitor (RLI) is induced in plants showing RNA interference. J Mol Evol. 2004:59(1):20-30.

36. Menke M, Chen I, Angelis KJ, Schubert I. DNA damage and repair in Arabidopsis thaliana as measured by the comet assay after treatment with different classes of genotoxins. Mutat Res. 2001;493(1-2):87-93.

37. Markmann-Mulisch U, Wendeler E, Zobell O, Schween G, Steinbiss HH, Reiss B. Differential requirements for RAD51 in Physcomitrella patens and Arabidopsis thaliana development and DNA damage repair. Plant Cell. 2007 . 19(10):3080-9.
38. Zhang C, Guo H, Zhang J, Guo G, Schumaker KS, Guo Y. Arabidopsis cockayne syndrome A-like proteins $1 \mathrm{~A}$ and $1 \mathrm{~B}$ form a complex with CULLIN4 and damage DNA binding protein $1 \mathrm{~A}$ and regulate the response to UV irradiation. Plant Cell. 2010;22(7):2353-69.

39. Hu Z, Cools T, Kalhorzadeh P, Heyman J, De Veylder L. Deficiency of the Arabidopsis helicase RTEL1 triggers a SOG1-dependent replication checkpoint in response to DNA cross-links. Plant Cell. 2015;27(1):149-61.

40. Murashige T, Skoog F. A revised medium for rapid growth and bio assays with tobacco tissue cultures. Physiol Plant. 1962;15(plant):473-97.

41. Yuan HM, LiU WC, LU YT. CATALASE2 coordinates SA-mediated repression of both auxin accumulation and JA biosynthesis in plant defenses. Cell Host Microbe. 2017;21(2):143-55

42. Liu WC, Li YH, Yuan HM, Zhang BL, Zhai S, Lu YT. WD40-REPEAT 5a functions in drought stress tolerance by regulating nitric oxide accumulation in Arabidopsis. Plant Cell Environ. 2017:40(4):543-52.

43. Gao X, Yuan HM, Hu YQ, Li J, Lu YT. Mutation of Arabidopsis CATALASE2 results in hyponastic leaves by changes of auxin levels. Plant Cell Environ. 2014;37(1):175-88

44. Liu W, Li RJ, Han TT, Cai W, Fu ZW, Lu YT. Salt stress reduces root meristem size by nitric oxide-mediated modulation of auxin accumulation and signaling in Arabidopsis. Plant Physiol. 2015;168(1):343-56.

45. Kobbe S, Trapp O, Knoll A, Manuss A, Puchta H. The Translesion polymerase zeta has roles dependent on and independent of the nuclease MUS81 and the helicase RECQ4A in DNA damage repair in Arabidopsis. Plant Physiol. 2015;169(4):2718-29.

46. Yao Y, Bilichak A, Golubov A, Kovalchuk I. ddm1 plants are sensitive to methyl methane sulfonate and $\mathrm{NaCl}$ stresses and are deficient in DNA repair. Plant Cell Rep. 2012;31(9):1549-61.

\section{Ready to submit your research? Choose BMC and benefit from}

- fast, convenient online submission

- thorough peer review by experienced researchers in your field

- rapid publication on acceptance

- support for research data, including large and complex data types

- gold Open Access which fosters wider collaboration and increased citations

- maximum visibility for your research: over $100 \mathrm{M}$ website views per year

At BMC, research is always in progress.

Learn more biomedcentral.com/submissions 